\title{
EDUCAÇÃO AMBIENTAL E GEOGRAFIA: UMA EXPERIÊNCIA INTERDISCIPLINAR NO SERIDÓ POTIGUAR
}

\author{
Adriana Claudia Câmara da Silva' ${ }^{1}$; Afonso Frazão Barbosa Júnior ${ }^{2}$; \\ Ana Luiza Cerqueira Lopes ${ }^{3}$; Leci Martins Menezes Reis ${ }^{4}$; Valdenildo Pedro da \\ Silva ${ }^{5}$ \\ ${ }^{1}$ Mestre em Biologia e Professora do Centro Federal de Educação Tecnológica do Rio \\ Grande do Norte (CEFETRN) \\ adriana@cefetrn.br \\ ${ }^{2}$ Graduando em Tecnologia em Gestão Ambiental no CEFETRN \\ frazaojr84@yahoo.com.br \\ ${ }^{3}$ Graduanda em Tecnologia em Gestão Ambiental no CEFETRN \\ analuizacl@yahoo.com.br \\ ${ }^{4}$ Mestre em Meio Ambiente e Desenvolvimento e Professora do CEFETRN \\ leci@cefetrn.br \\ ${ }^{5}$ Doutor em Geografia e Professor do CEFETRN \\ valdenildo@cefetrn.br
}

Recebido em maio de 2006 e aceito em outubro de 2006

\section{RESUMO}

Este trabalho é um relato de uma experiência do curso de atualização em educação ambiental e geografia do semi-árido para educadores da rede de ensino público dos municípios de Acari, Carnaúba dos Dantas e São José do Seridó, situados na região semiárida do estado do Rio Grande do Norte. Essa problemática veio à tona por ocasião da pesquisa que fora realizada nas cidades do semi-árido norte-riograndense durante o ano de 2005 e recebeu o título de Educação Ambiental - o estudo do semi-árido na educação básica do Estado do Rio Grande do Norte. A preocupação esteve centrada basicamente na ausência da discussão da semi-aridez e da desertificação no contexto do ensino e na realidade da população sertaneja. Em face disso estruturou-se um curso de formação continuada tendo como finalidade atualizar as temáticas de educação ambiental e da geografia do semi-árido no contexto da sala de aula da educação básica, a partir da aplicação de conteúdos e de metodologias dinamizadoras. A metodologia teórico-prática do curso ancorou-se no movimento "ação-reflexão-ação": a partir da análise da prática cotidiana dos alunos-professores pautada pela reflexão teórica para emergir uma nova prática nos processos de ensino e aprendizagem desses alunos. Nos encontros foram realizadas as oficinas em todos os módulos. Módulo I: Ética, Cidadania e Meio Ambiente; Módulo II: Biodiversidade da Caatinga; Módulo III: Desertificação e qualidade de vida; Módulo IV: Saneamento básico e ambiental; Módulo V: Métodos e Técnicas do Trabalho Científico; Módulo VI: Elaboração de Projeto interdisciplinar; Módulo VII: Seminário Integrador. Os processos de ensino, fundamentados pela dinâmica de grupo, foram orientados pelos princípios de uma nova concepção de Educação Ambiental (baseada em eixos temáticos) na qual o ser humano é responsável pela construção individual e social de sua existência. Como resultado os Eixos Temáticos dos projetos elaborados pelos profesores-alunos foram: Ética, Cidadania e Meio Ambiente. Biodiversidade: a Caatinga, Fundamentos da Educação Ambiental, Técnicas de Educação Ambiental, Projetos e atividades em Educação Ambiental, A Geografia do Semi-Árido, A Educação Ambiental como tema transversal, Impactos Ambientais e Legislação Ambiental,Desertificação e 
Qualidade de Vida, Desenvolvimento Sustentável,Gerenciamento de Resíduos Saúde e Meio Ambiente Domiciliar, Saneamento Básico e Ambiental, Educação Ambiental e Materiais Didáticos, Métodos e Técnicas do Trabalho Científico.Todos foram desenvolvidos nas oficinas módulos experiências de imersão no contexto da sala de aula tem contribuído para aprimorar e dinamizar a prática docente e tornar a temática da desertificação um conteúdo interdisciplinar cotidiano nos ensinos fundamental e médio básico das escolas locais.

PALAVRAS-CHAVE: Educação Ambiental, Geografia e Desertificação. 


\section{EDUCAÇÃO AMBIENTAL E GEOGRAFIA: UMA EXPERIÊNCIA INTERDISCIPLINAR NO SERIDÓ POTIGUAR}

\section{INTRODUÇÃO}

Este trabalho é um relato de uma experiência do Núcleo de Estudos do Semi-Árido (NESA) do Centro Federal de Educação Tecnológica do Rio Grande do Norte (CEFETRN) sobre o curso de atualização que vem sendo desenvolvido, tendo como tema: educação ambiental e geografia do semi-árido, para educadores da rede de ensino público dos municípios de Acari, Carnaúba dos Dantas e São José do Seridó. Esses municípios estão situados na região semi-árida do estado do Rio Grande do Norte, conforme mostrado na Figura 1.

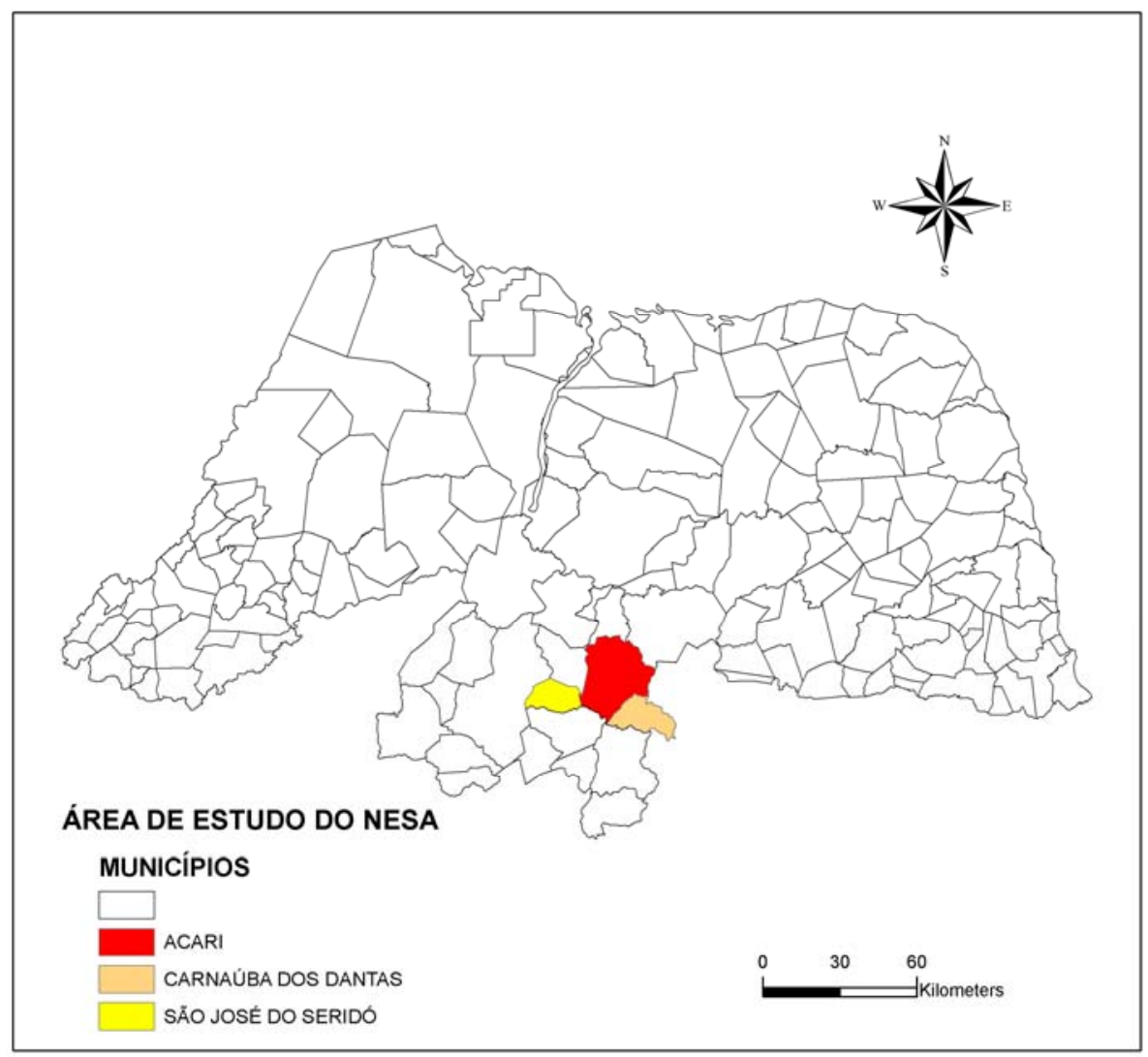

Figura 1. Mapa do Rio Grande do Norte destacando os municípios onde a pesquisa foi realizada.

Essa região é conformada como uma área em processo de desertificação, posto que apresenta um clima seco e um elevado déficit pluviométrico; possui uma formação geológica rica em minerais e solos que varia entre alta e baixa fertilidade natural, onde a cobertura vegetal é subdesértica e hiperxerófila. Trata-se de uma área encravada no Polígono das Secas, logo tem apresentado ao longo dos últimos tempos, secas constantes que têm penalizado e fustigado o homem do sertão norte-riograndense. Esse curso teve sua origem por ocasião da pesquisa do NESA que fora realizado no ano de 2005, nas escolas estaduais Dr. José Gonçalves Medeiros-Acarí/RN; Tomas Araújo -Acari/RN e nas 
municipais Instituto Municipal João Cândido Filho de Carnaúba dos Dantas/RN e Raul de Medeiros Dantas/São José do Seridó/RN e que recebeu o título de Educação Ambiental: o estudo do semi-árido na educação básica do Estado do Rio Grande do Norte. A problemática esteve centrada basicamente na ausência da discussão dos temas como: semiaridez e desertificação no contexto dos livros didáticos, mais precisamente os de geografia e ciências, no ensino de sala de aula e na realidade da população sertaneja.

Nessa pesquisa, detectou-se que $72 \%$ dos alunos das escolas investigadas apresentavam parcas discussões sobre a desertificação e semi-aridez, bem como os livros didáticos de geografia e ciências quase não faziam abordagem sobre esse fenômeno regional, além desse resultado, quando indagados os alunos a respeito dos temas que gostariam que fossem abordados nem tampouco as aulas dos professores faziam alusões a esses dois temas. Em sala da aula, em educação ambiental e geografia, 80\% dos entrevistados apontaram à necessidade de ter como em foco de discussão em sala de aula: o processo de desertificação.

Culminando com essa pesquisa, em outubro de 2005 o MEC lançou o edital 008PROEXT-2005 de chamada de projetos de extensão em que o NESA teve aprovado o projeto do curso de Capacitação de educadores do semi-árido potiguar para o combate a desertificação aos educadores da rede de ensino público dos municípios pesquisados. Esse projeto conta com o financiamento do Ministério da Educação, no valor de vinte e três mil duzentos e vinte três reais e vinte centavos. Como órgãos parceiros estão às prefeituras municipais de Acari, Carnaúba dos Dantas e São José do Seridó. Além disso, tem o apoio do Instituto de Desenvolvimento Econômico e Meio Ambiente do Rio Grande do Norte (IDEMA).

Esse curso tem como objetivo geral capacitar cento e oitenta professores do ensino fundamental e médio das escolas estadual e municipal de Acari, Carnaúba dos Dantas e São José do Seridó no RN, com uma carga horária de 180 horas-aula. Como atividade precípua promover a multiplicação de conhecimentos que contribuam com o combate a desertificação, bem como na difusão de conhecimentos de geografia e meio ambiente, no sentido de apoiar as comunidades locais a implementar um desenvolvimento socioambiental sustentável consoante com a realidade de desertificação em que vive a população local. Uma das metas propostas inicialmente por esse projeto era que ao seu termino viesse contribuir para um salto de qualidade ambiental no sentido da responsabilidade social de todos nós com a vida e o meio ambiente seridoense. A nossa preocupação era a de que os educadores dessas localidades tornassem mais informados e conscientes das necessidades de participação para a sustentabilidade do ambiente local que está na casa, na rua, na sala de aula, na vida socioespacial de cada um morador do sertão potiguar. Esse curso visa forma sujeitos a partir da realidade social em que vivem.

Trata-se de um curso, em nível de pós-graduação latu sensu, que tem como objetivos operacionais: selecionar e cadastrar conjuntamente com as secretarias municipais de educação, os professores de ensino fundamental e médio dos municípios envolvidos com esse projeto; elaborar material didático, contextualizado com a realidade social e ambiental do lugar; realizar oficinas temáticas com base na construção de material pedagógico; desenvolver dinâmicas que possibilitem o aprendizado e a participação de todo o público alvo; realizar aula de campo contextualizada coma a realidade em processos de desertificação; identificar as principais fontes causadoras dos processos de desertificação; provocar novas leituras do espaço geográfico do semi-árido e mudanças de atitudes no cotidiano dos novos multiplicadores; 
orientar a produção de cartilhas didáticas com o grupo multiplicador, fundamentada em princípios pedagógicos, envolvendo a temática desertificação; e realizar, durante o processo de desenvolvimento do curso, processos avaliativos que redimensionem a prática pedagógica dos professores-alunos; elaborar relatório final, contendo os passos das atividades realizadas.

O curso de atualização é formado por profissionais de vários campos do conhecimento, sendo composto basicamente por graduados em Pedagogia, Letras, História, Geografia, Geologia, filosofia, Matemática, Engenharia civil e de saneamento e Administração de Empresas. A maioria dos alunos do curso atua em sala de aula da educação básica como educadores e uma pequena parte é formada por profissionais que atuam na orientação educacional ou na equipe pedagógica da escola. $\mathrm{O}$ curso é predominantemente formado por pessoas do sexo feminino e por uma pequeníssima parte de pessoas do sexo masculino, com idades que variam entre 20 e 40 anos de idade.

O conteúdo do curso de atualização foi organizado em três módulos, sendo um teóricoprático, com 60 horas-aula e ministrado nas sextas e sábados, com início no mês de abril de 2006; o segundo, também tem uma carga horária de 60 horas-aula de teoria-prática e aconteceu durante a semana, nas salas de aula dos professores na educação básica, como a multiplicação das ações desenvolvidas nas aulas teóricas realizadas nas sextas-feiras ou nos sábados; por fim, o ultimo módulo com 60 horas-aula conjugava a vivência dos conteúdos dos módulos anteriores em sala de aula ou em outras atividades propostas pela coordenação. Convém salientar que, a realização desses módulos aconteceu concomitantemente, ou seja, simultaneamente ocorreram às ações programadas pelos módulos I, II,III,IV, V, VI e VII. Desde o início havia uma preocupação em remeter o aluno-professor à reflexão sobre os problemas que afetam a sua vida, a da sua comunidade, a de seu País e a do seu Planeta. Muitas das questões políticas, econômicas e sociais permeadas por elementos diretamente ligados à questão ambiental. Entendemos que é preciso que o aprendizado seja significativo, isto é, que o aluno-professor possa estabelecer ligações entre o que aprendeu e a sua realidade cotidiana, entre o que aprende a o que já conhece, e também que possa utilizar o conhecimento em outras situações.

\section{METODOLOGIA: OS PERCURSOS DE UMA EXPERIÊNCIA DE EDUCAÇÃO AMBIENTAL}

Para atender nossa proposta do curso de capacitação, as contribuições do pedagogo Paulo Freire nos foram primordiais, na medida em que a metodologia teórica-prática do curso ancorou-se no movimento "ação-reflexão-ação": a partir da análise da prática cotidiana dos alunos-professores, pautada pela reflexão teórica para o emergir de uma nova prática nos processos de ensino e aprendizagem desses alunos. Os processos de ensino, fundamentados pela dinâmica de grupo, foram orientados pelos princípios de uma nova concepção de Educação Ambiental, na qual o ser humano é responsável pela construção individual e social de sua existência. No caso, os eixos temáticos trabalhados no curso de atualização, partiram dos elencados pelos alunos e professores que participantes da pesquisa.

Assim, o nosso fazer pedagógico consolida-se a partir do momento em que foi possibilitado construir ações pedagógicas juntamente com os trabalhadores em educação e sua comunidade. Parece-nos que o processo de educação, voltado para um relacionamento

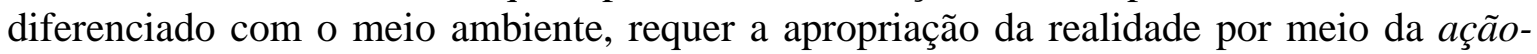
reflexão. E a construção coletiva dos saberes local, em um espaço ético cidadão, necessita 
dar conta dessa sociedade de risco que vem no seu cotidiano interferindo no meio, tal como, o avanço do processo de desertificação no Seridó norte riograndense. A educação ambiental na filosofia de Paulo Freire aponta como um processo libertador e humanístico, e que pode ser operacionalizado em duas fases. A primeira deve considerar a possibilidade de transformar as sociedades através das ações participativas e políticas dos estudantes. A segunda percebe que a pedagogia escolar cessa e tende a se transformar na pedagogia humana, num processo permanente de libertação. A descoberta da libertação, no entanto, não pode ser puramente intelectual, ela deve envolver a ação com a reflexão, a qual Paulo Freire denomina de práxis (FREIRE, 1987).

Dessa forma, o curso de atualização teve também, o amparo legal conforme a Lei n: 9.394 de 20 de dezembro de 1996, Cap. IV, Art. 44, inciso III e a Resolução: 01/2001 CNE/CES, de 03/04/2001 (MEC).O processo seletivo dos candidatos para o curso de atualização de educação ambiental e geografia do semi-árido, se fez fundamentado no Edital 01/2006 lançado pela Diretoria de Ensino do CEFETRN.

O curso está estruturado com uma carga horária de 180 horas-aula, sendo que 60 horas são presenciais e 120 horas são desenvolvidas no cotidiano da sua sala de aula, por meio de temáticas de educação ambiental e da geografia do semi-árido de forma interdisciplinar, no contexto da educação básica, a partir de conteúdos e aplicação de metodologias dinamizadoras, utilizando as disponibilidades sócio-culturais e recursos naturais do local.

Convém destacar que, os encontros presenciais ocorreram geralmente nas sextas-feiras e nos sábados pelas manhãs, previamente agendados com os alunos-professores e nas oficinas ocorriam à socialização das atividades e os relatos das oficinas desenvolvidas com os alunos durante a semana, experiências positivas e/ou negativas e possíveis ajustes. Os docentes do CEFETRN eram os mediadores nas trocas das experiências, acertos, conquistas e limitações, sempre na busca da melhoria, do ensino e da aprendizagem dos alunos seridoenses potiguares.

Almejando atingir os objetivos propostos, o curso foi planejado para ser trabalhado em sete módulos: oficinas configuradas no quadro 01.

Os módulos estão estruturados em oficinas e foram trabalhados por uma equipe interdisciplinar de professores e pesquisadores do CEFETRN composta por dois doutores, uma doutoranda, dez mestres e uma mestra pedagoga, além de dois alunos bolsistas dos cursos de graduação em Tecnologia em Controle Ambiental e Licenciatura Plena em Geografia.

Para o fazer interdisciplinar dessa equipe os encontros semanais ocorriam com objetivos de planejamentos holísticos; trocas de experiências e informações; seleção de conteúdos e metodologias trabalhadas e a serem desenvolvidas nas oficinas, além das produções extraclasse do aluno-professor nas suas salas de aula. 
Quadro 1: Distribuição dos módulos e os eixos temáticos do Curso de Atualização.

\begin{tabular}{|c|c|}
\hline Módulos & Oficinas e eixos temáticos \\
\hline $\begin{array}{l}\text { Módulo I } \\
\text { Ética, Cidadania e Meio } \\
\text { Ambiente }\end{array}$ & $\begin{array}{l}\text { - Fundamentos da Educação Ambiental } \\
\text {-Educação Ambiental como tema transversal }\end{array}$ \\
\hline $\begin{array}{l}\text { Módulo II - } \\
\text { Biodiversidade da Caatinga }\end{array}$ & $\begin{array}{l}\text { - A Geografia do Semi-Árido } \\
\text { - O que é desertificação ? } \\
\text { - Técnicas de Educação Ambiental }\end{array}$ \\
\hline $\begin{array}{l}\text { Módulo III - } \\
\text { Desertificação e qualidade } \\
\text { de vida }\end{array}$ & -Impactos Ambientais no solo e Legislação Ambiental \\
\hline $\begin{array}{l}\text { Módulo IV - } \\
\text { Saneamento básico e } \\
\text { ambiental }\end{array}$ & $\begin{array}{l}\text { Saneamento Básico e Ambiental; } \\
\text { Saúde e Meio Ambiente Domiciliar } \\
\text { Desenvolvimento Sustentável }\end{array}$ \\
\hline $\begin{array}{l}\text { Módulo V- } \\
\text { Métodos e Técnicas do } \\
\text { Trabalho Científico }\end{array}$ & $\begin{array}{l}\text { - Planejamento e execução da pesquisa em educação ambiental e } \\
\text { geografia } \\
\text { - Elaboração de Projetos de educação ambiental }\end{array}$ \\
\hline $\begin{array}{l}\text { Módulo VI- } \\
\text { Elaboração de Projeto } \\
\text { interdisciplinar }\end{array}$ & $\begin{array}{l}\text { - Orientação para elaboração do projeto interdisciplinar de educação } \\
\text { ambiental e geografia do semi-árido nas escolas dos alunos- } \\
\text { professores }\end{array}$ \\
\hline $\begin{array}{l}\text { Módulo VII- } \\
\text { Seminário Integrador }\end{array}$ & $\begin{array}{l}\text { - Avaliação do curso pelos professores-alunos; } \\
\text { - Exposição dos trabalhos produzidos; } \\
\text { - Solenidade de entrega dos certificados; } \\
\text { - Baile de encerramento. }\end{array}$ \\
\hline
\end{tabular}

\section{RESULTADOS E DISCUSSÃO: DESENVOLVIMENTO DOS MÓDULOS}

O curso teve seu lançamento numa tarde festiva na cidade de Acari no dia 07 de Abril de 2006, contando com a participação de todos os alunos dos demais municípios selecionados e de autoridades dos municípios envolvidos, além de alguns professores e diretores do CEFETRN, bem como dos bolsistas do projeto.

O módulo I também iniciou no dia 07/04/2006 às 18 horas com a realização de uma oficina, partindo dos informes gerais do curso; dinâmica de apresentação; formação de grupos; leituras, reflexões e resgate das práticas docentes tendo como aporte teórico o texto 01: Ensinar e aprender duas coisas diferentes. As idéias desse texto constituíram-se em suportes do início do curso. A autora desse texto nos diz que

ensinar e aprender são processos diferentes que envolvem sujeitos também diferentes: um educador e um educando. Ensinar e aprender, por envolver processos e sujeitos diferentes, supõe também métodos diferentes: os mecanismos e estratégias que o professor utiliza para desenvolver a lição de História são diferentes daqueles que o estudante utiliza para aprender essa mesma lição. O estudante vai recorrer, por 
exemplo, a associações com nomes ou episódios conhecidos ou vivenciados, enquanto que o professor estará se preocupando em reconstituir os autores consultados, buscar uma relação entre os acontecimentos, encontrar exemplos, etc. (TORRES, 2006, p.1).

Esse suporte teórico tem facilitado às discussões e reflexões das práticas pedagógicas no processo do ensino aprendizagem. Dano continuidade, no segundo dia do curso, a oficina continuou com a leitura do texto 02: A mudança começa em nós que culminou com a construção de um painel interdisciplinar (Figura 2), partindo das discussões como trabalhar na sala de aula o tema escolhido pela comunidade participante do projeto: a desertificação.

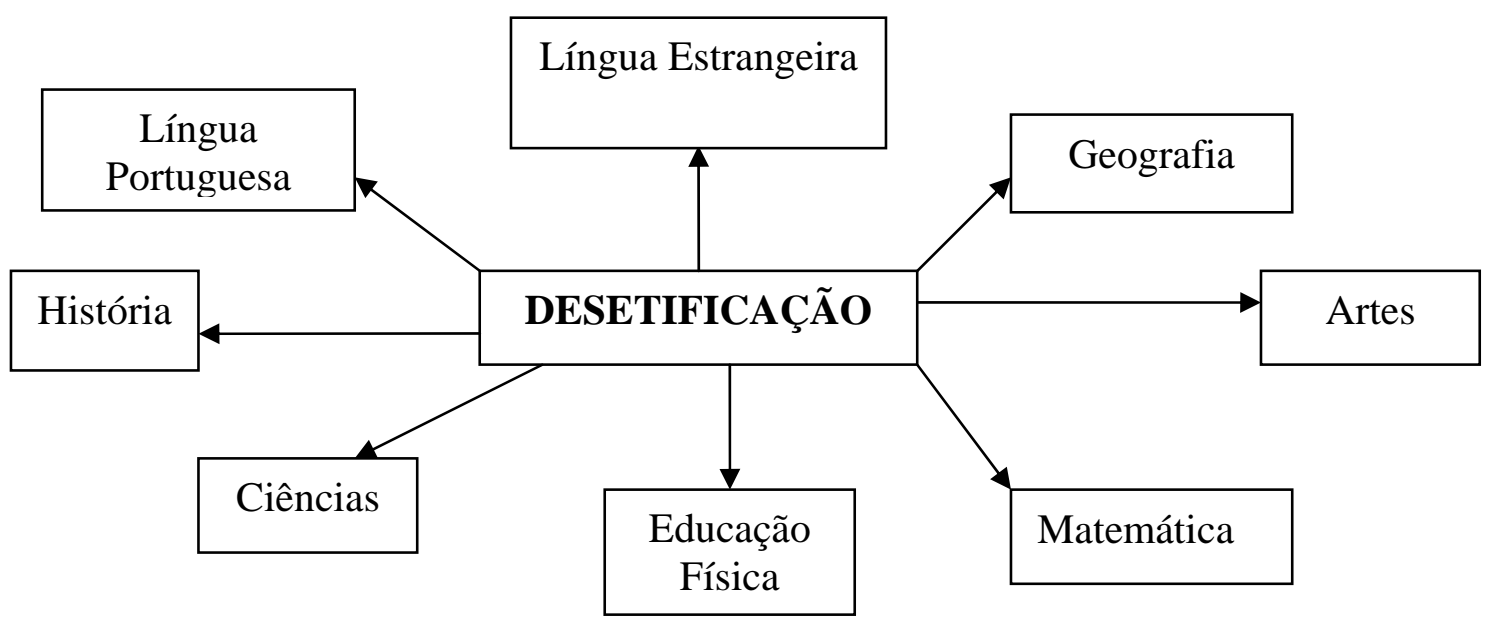

Figura 2: Painel interdisciplinar: desertificação

A discussão final prendeu-se aos fechamentos das indagações que se fizeram além das orientações que se fizeram necessárias para distribuir a atividade extra-classe, tendo como suporte o texto 03: Toca da raposa realiza atividades em educação ambiental. O material produzido na sala de aula dos alunos-professores constitui parte da produção da cartilha em educação ambiental, charge, histórias em quadrinho, musica, texto com ilustração, cordel, poesia, rap, peça teatral, desenhos, etc.

O módulo II foi realizado no dia 28 de abril de 2006 com início às 18 horas com dinâmica de motivação e a formação de grupo; socialização das atividades (dever de casa) formação de grupos; leituras, reflexões e resgate das práticas docentes, tendo como referencial o texto 01 - O que é desertificação.

Quebra de paradigmas (dinâmica dos provérbios) Texto 02 - Terra fértil vira barro na região do Seridó. Reflexão sobre desertificação e o espaço vivido no local. A oficina no segundo dia foi iniciada com a dinâmica: Pensar coletivamente para em seguida ser resgatado o texto 03 (Módulo I) - Toca da Raposa realiza atividades em educação ambiental, com a retomada do texto e orientações às atividades da aula prática sobre biodiversidade que esteve assim estrutura: coleta de material no campo (folhas das diversas espécies do bioma caatinga do local); oficina de confecção do painel da biodiversidade; a atividade extra-classe teve com aporte o texto: Como se faz o deserto e o material produzidos na sala de aula dos alunos-professores contribuiu com a produção de cartilha sobre educação ambiental, charge, histórias em quadrinho, musica, texto com ilustração, cordel, poesia, rap, peça teatral, desenhos. 
O módulo III foi trabalhado no dia 13 de maio de 2006 nos turnos matutinos e vespertinos para adequar as necessidades dos alunos-professores. Teve início às 08 horas com a socialização das atividades realizadas nas salas de aulas; formação dos grupos de trabalho; retomada do texto 01 do módulo II: Como se faz um deserto com contextualização da problemática ambiental local e em seguida leitura e discussão do texto 02 - Os solos; atividades de campo (coleta de amostras de solo); oficina de construção da modelagem do perfil do solo local; apresentação dos grupos e fechamento; Texto complementar: Um terrário para observar o ciclo da água Atividade extra-classe: construção de um terrário com os alunos, contextualizando com educação ambiental e o processo de desertificação no seridó.

O módulo IV foi realizado no dia 02 de junho de 2006 iniciando com a socialização das atividades de casa: construção do terrário; dinâmica de integração: idéias geram idéias; dialogação sobre a temática em foco; após as discussões formaram-se quatro grupos para a construção coletiva de um texto temático: lixo e saneamento; após essa construção foi socializado com o grande grupo. O texto 01 - Eu consumo tu consomes... ; serviu como suporte além do texto 02 - Idéia puxa Idéia...; Orientações para atividade de oficina de campo; Oficina nos supermercados, armazéns, feiras e ou estação de tratamento; Contextualização do texto com a oficina de campo; Pensar em grupo e elaborar uma atividade para ser desenvolvida em sua sala de aula; dinâmica: atitudes ecológicas; Atividade Extra-Classe: Aplicação na sua sala de aula da atividade pensada; Trazer no próximo encontro, um exemplar da produção de seus alunos.

O modulo V foi trabalhado no dia 10 de junho de 2006, nos turnos, matutinos e vespertinos para adequar as necessidades dos alunos-professores. Teve como tema gerador o planejamento e execução da pesquisa em educação ambiental e geografia do semi-árido; Socialização das atividades de casa: oficina nos supermercados, feiras e ou estação de tratamento de esgoto; Orientações do planejamento da pesquisa:

Projeto de pesquisa: apresentação, tema, delimitação, justificativa, formulação do problema, questões, construção de hipóteses, objetivos, métodos e técnicas, cronograma, notas e citações e referências; Execução da pesquisa: coletas de dados, população, amostras, apuração, análises e interpretação dos dados; Texto 01 - As etapas da pesquisa; leitura e discussões. Atividade extra-classe: elaboração de um projeto interdisciplinar para ser possivelmente desenvolvido na escola.

O Módulo VI foi trabalho no dia 28 e 29 de julho. Nesses encontros ocorreram às discussões, esclarecimento de dúvidas e orientações dos projetos interdisciplinares elaborados pelos profesores-alunos das escolas. As propostas foram todas contextualizadas com a realidade da comunidade escolar para possível execução das mesmas. Os eixos temáticos elencados pelos participantes foram: Ética Cidadania e Meio Ambiente; Biodiversidade: a Caatinga; Fundamentos da Educação Ambiental; Técnicas de Educação Ambiental; Projetos e atividades em Educação Ambiental; A Geografia do Semi-Árido; A Educação Ambiental como tema transversal; Impactos Ambientais e Legislação Ambiental; Desertificação e Qualidade de Vida; Desenvolvimento Sustentável; Gerenciamento de Resíduos; Saúde e Meio Ambiente Domiciliar; Saneamento Básico e Ambiental; Educação Ambiental e Materiais Didáticos.

O módulo VII foi efetuado no dia 12 de agosto com o tema, Seminário Integrador: o aluno realizou a avaliação individual do curso; ocorreu às exposições dos painéis temáticos 
produzidos pelos alunos durante as atividades extra-classe; solenidade de entrega dos certificados com a presença dos representantes do poder público dos três municípios abrangidos, os professores que contribuíram, além da direção geral e colegas das diversas áreas de nossa instituição educativa-tecnológica, o CEFETRN.

\section{CONCLUSÃO}

A prática pedagógica adotada no decorrer do curso, ação-reflexão-ação, envolve teorias práticas e dinâmicas na sala de aula de educação tem contribuído para aprimorar e dinamizar a prática docente e tornar a temática da desertificação um conteúdo interdisciplinar cotidiano no ensino básico nas escolas locais. Isso foi percebido nas falas dos alunos-professores, na participação dos alunos no transcorrer das oficinas. Foram bem expressivas conforme registros fotográficos e as listas de assinaturas de presença nas oficinas, trabalhos escritos e entregues durante o processo de ocorrência do curso, além da produção das atividades extra-classe mediante a riqueza das criatividades, arte e conteúdos desenvolvidos nas produções dos alunos.

Esses resultados nos remetem a Pedrini (1997, p.72) de que a educação ambiental como permeadora de uma educação transformadora e construtora de novas posturas, hábitos $e$ condutas é que comungamos que a reflexão de Freire poderá colaborar como uma das fundamentações aos projetos elaborados e a serem desenvolvidos juntos com os trabalhadores educacionais e suas respectivas comunidades. Isso porque entendemos que a educação ambiental será transformadora se for emersa nas raízes da própria comunidade, brotando nos diversos ramos das necessidades, credibilidades e reconhecimento dos saberes dos cidadãos munícipes.

\section{REFERÊNCIAS}

AZEVEDO, Israel Belo de. O prazer da produção científica: diretrizes para a elaboração de trabalhos acadêmicos. Piracicaba: Ed. da UNIMEP, 1998.

BRANCO, Samuel Murgel. O meio ambiente em debate. São Paulo: Moderna, 2004.

BRASIL. Fundação Nacional de Saúde. Manual de saneamento. 3. ed.rev.Brasília: Fundação Nacional de Saúde, 2004.

FREIRE, Paulo. Pedagogia do oprimido. 19.ed.Rio de Janeiro: Paz e Terra, 1987

IDEMA-RN. Diretrizes para política de controle da desertificação no Rio Grande do Norte. Natal: IDEMA, 2004.

MARANGON, Cristiane. Um terrário para observar o ciclo da água. Revista Nova Escola, São Paulo, v. 15, n. 89, p. 40-41, setembro. 2003

OLIVEIRA, F. S.; SILVA, A. C. C.; REIS, L. M. M.; SILVA, V. P. O estudo do semiárido no contexto da sala de aula: desafios da educação ambiental. In: I jornada nacional da produção cientifica em educação profissional e tecnológica, 2006, Brasília. 
PEDRINI, A. de G. Educação ambiental; reflexões e práticas contemporâneas. Petrópolis: Vozes, 1997

PROGRAMA NACIONAL DE EDUCAÇÃO AMBIENTAL - PRONEA: documento básico/Ministério do Meio Ambiente, Diretoria de educação ambiental; Ministério da Educação, coordenação geral de educação ambiental. Brasília, 2004.

SATO, Michele. Educação ambiental. São Carlos: Rima, 2004. 